\title{
An Android based Application for Determine a Specialized Hospital Nearest to Patient's Location
}

\author{
Muhammad Wasim Munir \\ Sir Syed University of \\ Engineering \& Technology, \\ Karachi \\ Main University Road, Karachi- \\ 75300, Pakistan
}

\author{
Syed Muhammad Omair \\ Sir Syed University of \\ Engineering \& Technology, \\ Karachi \\ Main University Road, Karachi- \\ 75300, Pakistan
}

\author{
M. Zeeshan UI Haque \\ Sir Syed University of \\ Engineering \& Technology, \\ Karachi \\ Main University Road, Karachi- \\ 75300, Pakistan
}

\begin{abstract}
Information and Communication Technologies (ICTs) are commonly using in healthcare organizations worldwide. The android operating system (AOS) based electronic devices such as Smartphones and computer tablets are extensively used for many purposes like instant messaging, gaming, word processing, Internet and download number of applications online. A rapid growth of android phones has enabled to replace PC's software and other licensed software development technologies. There are different kinds of healthcare applications developed in android Smartphones which help patients and their caregivers to reduce time and cost efficiency. In this research work, an application is developed that locates the nearest hospital about five $\mathrm{km}$ radius with the desired medical specialist. The nearest position of hospitals is calculated with a built-in feature of Global Positioning System (GPS) in Smartphones and finds the route from their current location through Google Map application Program Interfaces (API). An informative survey of different hospitals in Karachi is conducted to obtain an accurate list of doctors available in each hospital. With the help of this application, a patient can find the nearest hospital according to specialized consultant availability. A comprehensive profile of doctor and hospital is available in the application including the website, mailing addresses and contact numbers.
\end{abstract}

\section{General Terms}

Information and Communication Technology (ICT), Global Positioning System (GPS), Android operating system (AOS), Android Software Development Kit (ASDK), Application Program Interfaces (API).

\section{Keywords}

ICT in Healthcare, Smartphone application, Google MAP, MHealth

\section{INTRODUCTION}

The latest Smartphones made dramatic breakthroughs in processing power, higher random access memory, and secondary storage along with the number of extra features like internet access have opened doors to a broad range of applications development. An Android operating system (AOS) commonly used by Smartphone manufactures because it is an open source operating system based on the Linux kernel and designed primarily for touch screen mobile devices such as Smartphones and tablet computers. The internal hardware of Smartphones especially sensors like proximity, accelerometer and gyroscope sensors are used by some applications to respond to additional user actions [1].

There are different applications (apps) categories available for download from the online Google play store. Everyday thousands of new apps are uploaded in their online database. A number of applications related to healthcare are available in the medical category which is helpful in the diagnosis of vital sign parameters, vaccinations schedule, medicine reminder etc [2]. These kinds of applications are lies in mobile-health (mhealth) technology. Some applications determine the location of health clinics, healthcare centers and city hospitals. Search the nearest hospital with the specialty in the city of Karachi is the unique idea of this application. Authentic and up-to-date information are available about each hospital and doctor. Below is the background information about choosing the AOS platform for this application.

\subsection{Android Devices}

Generally, AOS devices are available with a merger of open source programming and proprietary software but with AOS source code released by Google Inc. under the open source licenses agreement [3]. Originally AOS was developed by Android Inc. in October 2003 that Google supported financially and later purchased it in 2005. Android was revealed in 2007 in conjunction with the founding of the Open Handset Alliance; an association of hardware, software and telecommunication companies dedicated to moderate open standards for Smartphone and other cellular devices [4].

Android is popular in all kinds of technical fields that require a user friendly, low-cost and customizable software or applications for high-tech devices. Due to Android open source style, it encouraged software developers worldwide and devoted them to use the Android platform as a base for Smartphones and PC tablets related projects that add new features for advanced users [5]. The other operating system's developers are also making their project in AOS for android devices to achieve more success. This kind of accomplishment made a target for patent litigation as part of Smartphone wars between technology manufacturers [6].

AOS based devices find more consumer demands comparatively to Microsoft Windows, Apple iOS and Mac OS $\mathrm{X}$ devices combined in last three years. As of July 2013 the Google Play store has had over one million Android apps published and over fifty billion times apps downloaded. A developer survey has been conducted in April-May 2013 where $71 \%$ of apps developers develop for Android devices [7]. In 2014, Google Inc. disclosed that there were over one billion Android users that have been active for a month, up from 538 million in June 2013 [8].

\subsection{GPS in Smartphone}

Global Positioning System (GPS) enabled navigation in devices that precisely determines geographical location by receiving GPS co-ordinates information from the GPS satellites. Originally, it was only used by the United States military, but later this service is available freely worldwide 
and now most receivers are integrated into Smartphones, PC tablets, airplanes, tracking devices and automobiles [9]. At present, people feel more convenient to just use their Smartphone built-in GPS as navigation tools instead of a separate GPS device. Smartphone navigation typically gets free and speedy automatic updates as compare with commercial GPS devices. Also GPS is widely used for tracking the children and ageing people suffering from dementia and Alzheimer's diseases [10].

\subsection{Google Map APIs}

Google Maps are commonly used to determine the destination location, calculate distance and approximate time to reach a destination point from your current location. Basically, Google Maps have an extensive array of application program interfaces (APIs) that let you embed the great functionality and effectiveness of Google Maps into your Smartphone applications. Google gives by means of Google play a library for using Google Maps into Smartphones application. At present, Google Maps Android API V2 are available that provides improvements to the older API version [11].

The Google Map library gives the com.google.android.gms.maps.MapFragment class and the MapView class for displaying the map component. To access the Google Maps servers through the Maps API we have to add a Maps API key to Smartphone application. The key is free and can be used with any application that calls the Maps API, and it supports many users. Maps API key can be achieved from the Google APIs Console by providing application of signing certificate and its package name. The key is included in the application by adding an element AndroidManifest.xml file [12, 13].

\section{METHODOLOGY}

This research work was conducted in two steps. The first step was an informative survey and it conducted to gather the latest information about hospitals and doctors. The second step was to implement an application for android Smartphones, so that it will be available to all android users. Later it will be implemented for other mobile operating system. Figure 1 shows the flowchart of the whole project.

\subsection{Informative Survey}

The first step was to collect authentic information about doctors and hospitals that would be used in the application database. For this purpose an informative paper based survey was conducted in eighteen major hospitals in Karachi with the aim of acquiring valid information such as a hospital name, a list of specialized doctors, hospital contact numbers and web addresses. From these hospitals, ten categories of doctors were generated in accordance with their expertise in each division such as General Physician, Cardiologists, Dermatologists, Gynecologists, Child Specialists (Pediatrics), ENT Specialist, Neurologist, Ophthalmologists, Diabetologists and Dentists shown in Figure 2.

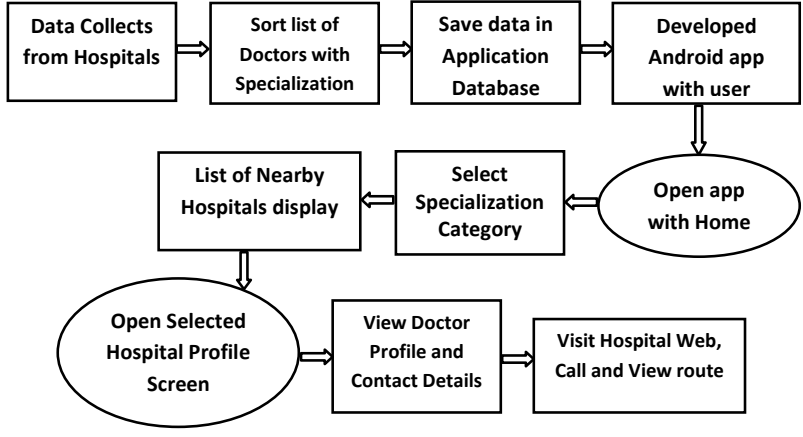

Fig 1: Flowchart of Project Implementation

\subsection{Development Tool Kit}

This application is developed in Java Programming Language by using the Eclipse Ganymede Integrated Development Environment (IDE). Android Software Development Kit (ASDK) was used which includes a variety of custom tools that help to develop mobile applications on an android platform [14] and the Android Emulator and the Android Development Tools (ADT) plug-in for Eclipse [15].

The user interface of the application is kept simple and understandable. A common user can easily understand the functionality of this application. The icons are selected in such a way that the user can easily understand and reached the desired information. The screens were designed in XML and the basic logic was written in Java. The web service is used to connect the android device with Google Libraries in PHP. Google Maps API has been used to make it easy for the user to discover the nearest hospitals according to specialization.

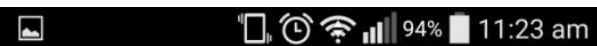

\section{CATEGORIES}
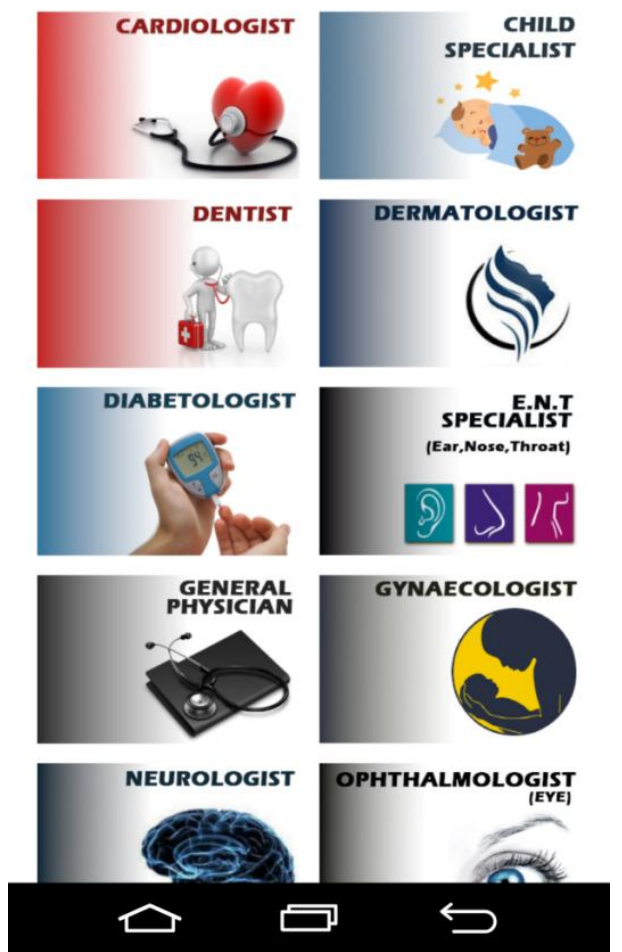

Fig 2: Category Screen Display 
Table 1: Menu of Application

\begin{tabular}{|c|l|}
\hline Screen & \multicolumn{1}{|c|}{ Features } \\
\hline Splash Screen & Click on icon to open app \\
\hline Home Screen & $\begin{array}{l}\text { Main screen that show all the } \\
\text { specialization fields }\end{array}$ \\
\hline $\begin{array}{c}\text { Hearby } \\
\text { Screen }\end{array}$ & $\begin{array}{l}\text { A list display of five km radius hospitals } \\
\text { from the user's current location shown in } \\
\text { Figure 3 }\end{array}$ \\
\hline $\begin{array}{c}\text { Single Hospital } \\
\text { Profile Screen }\end{array}$ & $\begin{array}{l}\text { This screen contains a brief introduction } \\
\text { of the hospital }\end{array}$ \\
\hline $\begin{array}{c}\text { Single Doctor } \\
\text { Profile Screen }\end{array}$ & $\begin{array}{l}\text { This shows the specialized doctor's } \\
\text { name along with contact numbers and } \\
\text { website of hospital }\end{array}$ \\
\hline $\begin{array}{c}\text { Hospital } \\
\text { Website Screen }\end{array}$ & $\begin{array}{l}\text { It opens the hospital webpage on the } \\
\text { browser of the android device }\end{array}$ \\
\hline $\begin{array}{c}\text { Map View } \\
\text { Screen }\end{array}$ & $\begin{array}{l}\text { The user can view the route to the } \\
\text { desired hospital with the help of Google } \\
\text { Map }\end{array}$ \\
\hline
\end{tabular}

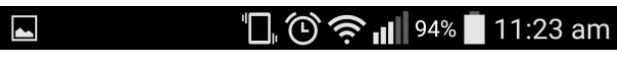
NEARBY HOSPITALS

PATEL HOSPITAL

DOW UNIVERSITY HOSPITA...

RAB MEDICAL CENTRE

SHAN HOSPITAL

KARACHI INSTITUTE OF HE...

TABBA HEART INSTITUTE

IBN-E-SEENA
Table 2: Unit Testing Results

\begin{tabular}{|l|l|l|}
\hline No. & \multicolumn{1}{|c|}{ Test Case } & \multicolumn{1}{c|}{ Expected Result } \\
\hline 1 & $\begin{array}{l}\text { When pressed the } \\
\text { application icon on } \\
\text { Smartphone }\end{array}$ & $\begin{array}{l}\text { Open application and show } \\
\text { splash screen and then home } \\
\text { screen containing category } \\
\text { grids }\end{array}$ \\
\hline 2 & $\begin{array}{l}\text { When pressed the } \\
\text { category icon }\end{array}$ & Show a list of nearby hospitals \\
\hline 4 & $\begin{array}{l}\text { When pressed the } \\
\text { hospital name icon }\end{array}$ & $\begin{array}{l}\text { Open the hospital profile } \\
\text { containing "View Doctor" } \\
\text { button }\end{array}$ \\
\hline 5 & $\begin{array}{l}\text { When pressed the } \\
\text { "View Doctor" } \\
\text { button }\end{array}$ & $\begin{array}{l}\text { Show a doctor profile having } \\
\text { contact and web address of the } \\
\text { hospital }\end{array}$ \\
\hline 6 & $\begin{array}{l}\text { Pressed the } \\
\text { "Contact number" } \\
\text { button }\end{array}$ & $\begin{array}{l}\text { Open the dialer of the phone } \\
\text { with the number already } \\
\text { written }\end{array}$ \\
\hline 7 & $\begin{array}{l}\text { Pressing the } \\
\text { "Website Address" } \\
\text { button }\end{array}$ & $\begin{array}{l}\text { Open the hospital website on } \\
\text { the browser of the phone }\end{array}$ \\
\hline 8 & $\begin{array}{l}\text { On pressing the } \\
\text { "Show } \\
\text { button Map" }\end{array}$ & $\begin{array}{l}\text { Show the route to the selected } \\
\text { hospital from the specified } \\
\text { source address }\end{array}$ \\
\hline
\end{tabular}

\subsection{Unit Testing}

In unit testing, various modules have been tested individually. This has been done manually to test if the expected result is actually seen on the screen. Table 2 listed the various unit testing results used for the checking for an application accuracy and efficiency.

\subsection{Compatibility Testing}

This application was mainly designed for android Smartphone version KitKat (4.4-4.4.4) as it helps users to find doctors and hospitals nearest to them according to their requirement. Different android phones have different screen sizes and resolution. This application has been made compatible with android devices regardless of their screen sizes and android KitKat and older versions.

\subsection{Location Testing}

A testing was carried out on different centralized locations of the city as mentioned in form of coordinates in Figure 4. This shows the availability of nearby hospitals in the application on a particular point. The specialized hospitals are more in the city center coordinates compared with other areas.

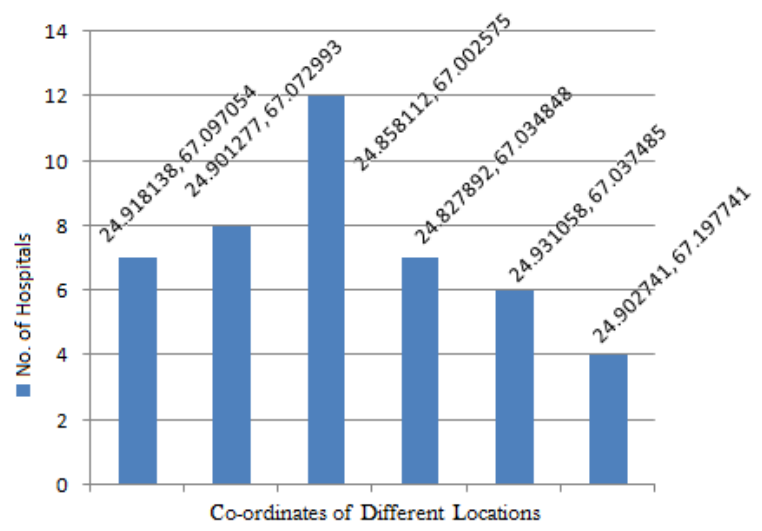

Fig 4: Number of Hospitals on Different Locations

\subsection{Graphical User Interface}

The Graphical User Interface (GUI) is quite simple and userfriendly of this application. Table 1 listed the main screens and the various features used in this application.

\section{RESULTS}

After the completion of application coding, basic syntax semantic and logical errors were removed. The following software test has been applied to make it bug free application. 


\section{FUTURE ENHANCEMENT}

Currently, this application shows the static list of doctors available in the particular hospital. This application can be enhanced to provide real-time information about the doctor present in particular time in the specific hospital. This application is designed and tested within the Karachi city and possibly not work outside the city at the moment. Furthermore, this application can be upgraded to cover more cities and all major hospitals of Pakistan. Presently, a radius of five $\mathrm{km}$ is fixed in the coding and in later version user can be select their specific radius by their own. This application is designed for android devices, later it will be designed for iOS, windows OS and other popular mobile operating systems. A questionnaire survey will be helpful in determining the benefits and usability of this application in general users.

\section{CONCLUSION}

In this study, a basic and up-to-date medical category application is designed to help the patients and caregivers to determine the nearest hospital with a specific specialization field. The hospital names along with their address and route are determined by Smartphone GPS receiver within five $\mathrm{km}$ of radius. With the help of Google Map, the distance and route to each of the hospital is displayed for the user. This application is greatly useful in emergency cases as well as for the non-resident person of the city of Karachi. Specialized list of doctors in each hospital in a single application is also useful for later appointments. The future scope of this application is to develop and determine the availability of specialist doctor on a real-time basis near patient's location. This development will also give an opportunity to book online appointment which facilitates the patients by saving the time.

\section{ACKNOWLEDGMENT}

The authors would like to thanks Mubashir Hussain, Fahad Aslam, Waqas Lohdi, Sibghatullah and Wareesha Khan for their efforts gathering the doctors and hospital data from different hospitals in Karachi.

\section{REFERENCES}

[1] Akash Borate, Ketan Bhapkar, Darpan Sharma. "Android Based Fuzzy Inference System to Control the Fan Speed". Journal of Harmonized Research in Engineering 2(1), pg 69-74, 2014

[2] Google Play Store, https://play.google.com/store/apps/category/MEDICAL Accessed on April 25, 2015

[3] Amit M. Farkade, Sneha R. Kaware. "The Android- A Widely Growing Mobile Operating System With its Mobile based Applications". International Journal of Computer Science and Mobile Applications", Vol.3 Issue. 1, pg. 39-45, January 2015,
[4] Sana, Dr. Ravindra Kumar, "Application Development in Android". International Journal of Advanced Research in Computer and Communication Engineering Vol. 3, Issue 6, June 2014

[5] Apoorva Prakash M V, Dr. M C Padma. "BatteryBandwidth Based Handover Framework for 3G/WLAN Using Android Handheld Devices". Int. Journal of Engineering Research and Applications, Vol. 4, Issue 6( Version 5), pp.33-38, June 2014

[6] J.A. Botía, D. Charitos. Workshop Proceedings of the 9th International Conference on Intelligent Environments. IOS Press, pg 208-209, July 2013

[7] Okediran O. O., Arulogun O. T. and Ganiyu R. A. "Mobile Operating Systems and Application Development Platforms: A Survey". Journal of Advancement in Engineering and Technology, Volume 1/Issue 4 August 08, 2014

[8] Pothumarthy Dharmeendra, B. Chinna Subbanna, "Design of a Portable Touchscreen Interface for Home Automation". International Journal of Scientific Engineering and Technology Research, Vol. 3 Issue 30. October 2014

[9] Muhammad Wasim Munir, Semi Perälä and Kari Mäkelä. "Utilization and Impacts of GPS Tracking in Healthcare: A Research Study for Elderly Care". International Journal of Computer Applications 45(11):35-37, May 2012

[10] Munir Muhammad Wasim, Mäkelä Kari, Perälä Sami. Assessment of GPS Tracking Devices for Elderly Care. International Hyvite Symposium on Wellbeing Technology, Tampere 2010:4;21

[11] Yimeng Wu, Zhixue Liang, Liming Liu. "Design and implementation of tourism information system based on Google Maps API". 21st International Conference on Geoinformatics, June 2013

[12] Tsai, V.J.D., Chun-Ting Chang. "Three-dimensional positioning from Google street view panoramas" IET Image Processing (Volume:7 ， Issue: 3 ) pg 229-239 April 2013

[13] Google Maps Android API v2. https://developers.google.com/maps/documentation/andr oid/start Accessed on April 25, 2015

[14] Android Studio IDE. https://developer.android.com/sdk/index.html Accessed on April 20, 2015

[15] Installing the Eclipse Plugin. http://developer.android.com/sdk/installing/installingadt.html Accessed on April 20, 2015 